\title{
Caninos permanentes retidos por palatino: diagnóstico e terapêutica - uma sugestão técnica de tratamento
}

\author{
Mario Cappellette*, Mario Cappellette Jr.**, Luciana Cappellette Monteiro Fernandes ${ }^{\star \star \star}$, Arnaldo Pinto de

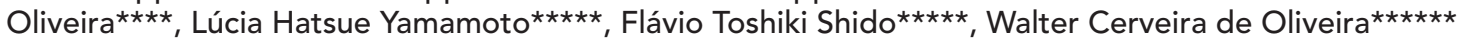

\begin{abstract}
Resumo
Os dentes seguem uma seqüência de erupção favorável no desenvolvimento da oclusão normal, mas algum distúrbio desse mecanismo, nesse período de transição da dentadura mista para a permanente, pode levar a alterações na seqüência ou mesmo no trajeto de erupção, levando a impactação de dentes. Os caninos superiores permanentes, depois dos terceiros molares, apresentam maior ocorrência de impactação, especialmente na região palatina, mesmo na presença de espaço suficiente para o seu alinhamento na arcada dentária. Na impossibilidade do diagnóstico precoce, esforços serão empregados para reposicionar o dente no arco dentário evitando sua extração, dada a sua importância no equilíbrio, harmonia e função do arco dentário. Nos casos não diagnosticados ou tratados inadequadamente podem ocorrer perturbações mecânicas, infecciosas ou neoplásicas. O prognóstico depende da posição do canino em relação às estruturas adjacentes e à possibilidade de movimentação ortodôntica. O presente trabalho aborda os principais fatores a serem considerados nos casos de caninos superiores permanentes impactados, tais como processo de erupção, etiologia, diagnóstico e uma forma de tração proposta para caninos impactados. Também será apresentado um caso clínico em que se optou pelo tratamento ortodôntico-cirúrgico, cuja técnica de tração tem-se mostrado bastante eficiente nos casos de impactação de caninos no palato.
\end{abstract}

Palavras-chave: Canino impactado superior. Etiologia. Impactação dentária.

\section{INTRODUÇÃO}

Os caninos superiores permanentes desempenham um importante papel no estabelecimento e manutenção da forma e função da dentição, sendo sua presença no arco dentário fundamental para o estabelecimento de uma oclusão dinâmica balanceada, além da estética e harmonia facial. Assim, dada a sua importância no arco dentário, diante de uma impactação do canino superior permanente, esforços deverão

* Professor do Curso de Especialização do Centro de Aperfeiçoamento Profissional e Especialização do Sindicato dos Odontologistas do Estado de São Paulo (CAPE - SOESP). Professor do Curso de Especialização em Ortodontia e Ortopedia Faciaal da Associação Brasileira de Odontologia - Secção São Paulo.

** Mestre em Ortodontia e Ortopedia Facial pela UNICASTELO. Doutor em Ciências da Saúde - Departamento de Otorrinolaringologia e Cirurgia de Cabeça e Pescoço da Escola Paulista de Medicina - UNIFESP Especialista em Radiologia. Coordenador do Curso de Especialização em Ortodontia e Ortopedia Facial da Associação Brasileira de Odontologia - Secção São Paulo e FAMOSP.

*** Professora do Curso de Aperfeiçoamento do Centro de Aperfeiçoamento Profissional e Especialização do Sindicato dos Odontologistas do Estado de São Paulo (CAPE - SOESP)

**** Especialista em Ortodontia e Ortopedia Facial pela UNICASTELO.

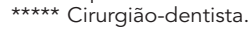

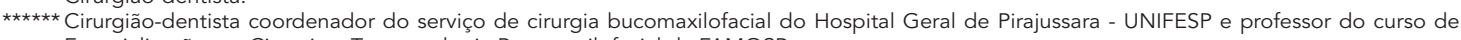
Especialização em Cirurgia e Traumatologia Bucomaxilofacial da FAMOSP. 
ser empregados para manter o dente evitando sua extração.

O canino superior tem um longo e complexo caminho de erupção, de seu local de formação (lateral à fossa piriforme) até sua posição final de erupção. Além disso, leva duas vezes mais tempo para completar a sua erupção e portanto torna-se mais susceptível a sofrer alteração na trajetória de erupção desde a odontogênese até o estabelecimento da oclusão normal. Isto pode acabar resultando em erupção ou impactação por vestibular ou palatino ${ }^{1}$.

A localização do canino impactado pode ser realizada por meio de exames clínicos e radiográficos, e é fundamental para o correto planejamento e conduta do tratamento a ser realizado.

Quando não diagnosticado e tratado, caninos superiores impactados podem causar perturbações mecânicas, infecciosas e neoplásicas.

O prognóstico do tratamento depende da posição do canino em relação aos dentes adjacentes e sua altura no processo alveolar. Também se deve levar em consideração a possibilidade do canino impactado não se movimentar ortodonticamente. Neste caso, será necessária a sua extração e o espaço poderá ser ocupado pelo premolar ou por uma prótese.

Este trabalho tem como objetivo revisar aspectos referentes ao processo de erupção do canino e sua importância estética e funcional na dentição; a etiologia, diagnóstico e conduta clínica quando de sua impactação e/ou erupção ectópica. Também será apresentado um caso clínico com proposição de tratamento utilizada em nossa clínica.

\section{CONSIDERAÇÕES QUANTO AO PROCESSO ERUPTIVO E ETIOLOGIA DA IMPACTAÇÃO}

Bishara $^{3}$ enumerou causas locais e gerais para a impactação do canino superior. As causas gerais incluem deficiências endócrinas, doenças febris e irradiação. Relatou que as causas mais comuns são as locais e são resultados de um ou a combinação dos seguintes fatores: Tamanho dental - discrepância do comprimento do arco, retenção prolongada ou perda precoce do canino decíduo, posição anormal do germe dental, presença de uma fenda alveolar, anquilose, formação cística ou neoplásica, dilaceração da raiz, origem iatrogênica, por exemplo, o reposicionamento iatrogênico do incisivo lateral adjacente no caminho de erupção do canino e condição idiopática com nenhuma causa aparente.

As causas gerais podem levar a retardos generalizados na erupção dos dentes e assim afetar a erupção do canino. As causas locais podem influenciar mais especificamente os caninos ${ }^{12,23}$.

De acordo com Moyers (1991 apud ALMEIDA et al. ${ }^{1}$ ), citado por Almeida et al. ${ }^{1}$, as causas podem ser primárias e secundárias. Enumerou como causas primárias: 1 ) reabsorção radicular do dente decíduo; 2) trauma dos germes dos dentes decíduos; 3) disponibilidade de espaço no arco; 4) rotação dos germes dos dentes permanentes; 5) fechamento prematuro dos ápices radiculares; 6) irrupção de caninos em áreas de fissuras palatinas; e como causas secundárias: 1) pressão muscular anormal; 2) doenças febris; 3) distúrbios endócrinos; e 4) deficiência de vitamina D.

Segundo Ries Centeno (1986 apud SANI$\mathrm{TÁ}^{22}$ ), a retenção tem antes de tudo, uma causa mecânica. Um obstáculo impede o trajeto de erupção normal do dente. Ele cita outras causas da retenção dentária: razões embriológicas, obstáculos mecânicos e causas gerais: enfermidades gerais em relação direta com as glândulas endócrinas, podem ocasionar transtornos na erupção, nas retenções e na ausência de dentes.

Segundo Becker et al. ${ }^{2}$, esta íntima relação entre o canino e a raiz do incisivo lateral superior sugere que este último ofereça uma guia que pode ser um fator significante na erupção normal do canino. Parece haver dois processos que podem causar o deslocamento do canino para o palato, o primeiro é a ausência de guia pelo incisivo lateral abrindo um novo caminho 
de erupção em direção ao palato. O segundo é em estágios mais avançados quando o canino, partindo de uma base óssea mais larga, desce em sentido oclusal, atravessando a crista óssea alveolar que se estreita progressivamente.

Jarjoura et al. ${ }^{12}$, relataram alta incidência de impactações do canino por palatino associadas com ausência do incisivo lateral ou de tamanho diminuído. Contudo, também é possível que a posição ectópica do incisivo lateral esteja obstruindo o caminho de erupção normal do canino. Isto pode ajudar a explicar a alta incidência de reabsorção radicular de incisivos laterais de tamanho normal adjacentes a caninos impactados. Jacoby ${ }^{11}$ concluiu que $85 \%$ dos casos de caninos superiores retidos por palatino têm espaço suficiente no arco e argumentou que uma deficiência no comprimento do arco levará somente o canino a erupcionar por vestibular. Excluindo a possibilidade do germe dentário poder ter se formado palatinamente, a explicação para a impactação palatina pode ser um espaço excessivo na área do canino que permitirá ao dente se mover palatinamente no osso e encontrar um local atrás dos germes dos outros dentes. Este espaço pode ser criado por (1) crescimento ósseo excessivo na área do canino, (2) agenesia ou hipodesenvolvimento do incisivo lateral e (3) erupção estimulada do incisivo lateral ou primeiro premolar.

Há autores que defendem que o posicionamento ectópico do canino esteja fortemente ligado a fatores genéticos. Peck et al. ${ }^{16,17}$, afirmaram que a etiologia do deslocamento da maioria dos caninos para palatino e sua subseqüente impactação é primariamente de origem genética. Segundo os autores, este fenômeno costuma ocorrer em associação com outros fatores controlados geneticamente. Dentre eles estão:

1) A ocorrência concomitante com outras anomalias dentárias como alterações de forma, tamanho e número de dentes.

2) Relatos de incidência bilateral de 17 a $45 \%$ dos casos de desvio palatino do canino, apontam para o mecanismo genético como fator etiológico intrínseco.

3) A ocorrência ligada ao sexo, com prevalência maior para o sexo feminino e em grau semelhante a outras anomalias dentárias de origem genética.

4) A incidência alta nos membros de uma mesma família juntamente com outras anomalias dentárias.

5) Diferenças de ocorrência em grupos populacionais, com maior incidência em europeus. Os autores afirmaram que exames radiográficos e o histórico familiar podem auxiliar no reconhecimento precoce da anomalia. A remoção do canino decíduo pode melhorar a posição do canino impactado no palato, facilitando assim o tratamento ortodôntico para seu reposicionamento.

A espessura do folículo dentário dos caninos, também, é vista como causadora das reabsorções dos incisivos laterais e o alargamento do espaço folicular foi citado como um dos fatores etiológicos para a retenção dos caninos superiores $^{25}$. Entretanto, Ericson e Kurol ${ }^{6}$ verificaram alterações dimensionais dos folículos dos caninos em apenas $22 \%$ dos casos relacionados às reabsorções dos incisivos laterais. As larguras dos folículos dentários dos caninos foram medidas em radiografias, sendo que 19\% dos caninos impactados apresentavam a largura máxima entre 3 e $5 \mathrm{~mm}$ e em $81 \%$ dos caninos impactados a largura estava abaixo de $3 \mathrm{~mm}$.

Segundo Brin et al. ${ }^{4}$, o trauma de dentes decíduos poderia afetar o desenvolvimento de seus sucessores permanentes no futuro como relatado em casos de incisivos mal alinhados e transposições dentárias. Fraturas das arcadas também foram associadas com impactação do canino. No primeiro de dois casos apresentados pelos autores, a raiz de um incisivo lateral direito estava encurtada, provavelmente, como resultado de injúria traumática, seguida de tratamento endodôntico e embargo de formação radicular. 


\section{DIAGNÓSTICO}

O diagnóstico da impactação, após a anamnese, é realizado por meios dos exames clínico e radiográfico. $\mathrm{Na}$ anamnese é importante observar a idade do paciente e seus antecedentes familiares de agenesia ou retenções dentárias. A cronologia de erupção relacionada às radiografias pode distinguir fases normais, como a de "patinho feio", de possíveis anomalias dentárias.

Segundo Bishara ${ }^{3}$, os principais sinais a serem observados no exame clínico são: atraso de erupção após a idade de 14 anos, retenção prolongada do canino decíduo, elevação da mucosa labial ou palatina, migração distal do incisivo lateral superior, com ou sem desvio da linha mediana. A ausência de elevação da mucosa gengival em idades prematura não deve ser tida como indicativo de impactação. Em um estudo com 505 crianças entre 10 e 12 anos de idade, constatou-se que, aos 10 anos, 19\% das crianças não apresentavam elevação da mucosa; aos 12 anos, 5\% e, mais tarde, somente 3\%.

Geralmente, em 70\% dos casos, um canino retido pode ser palpado. Por outro lado, de acordo com Becker (1998 apud ALMEIDA et al. ${ }^{1}$ ), se o contorno ósseo for côncavo, não se deve deixar de realizar a palpação pela palatina, para verificar se o canino se encontra localizado nesta região.

\section{EXAME RADIOGRÁFICO}

O exame radiográfico é imprescindivel na elaboração do diagnóstico, comprova a presença do canino em questão e o localiza dentro do osso maxilar no sentido vestíbulo-lingual, cérvico-oclusal e mésio-distal. Também o relaciona com as estruturas e dentes adjacentes. Ainda no exame radiográfico devem ser diagnosticados os aspectos inerentes ao canino, como formação e morfologia radicular, presença de cisto dentígeno etc...

Diferentes técnicas de diagnóstico por imagem podem ser empregadas com a finalidade de localizar os caninos não irrompidos. As mais comuns são: radiografias periapicais, radiografias oclusais, radiografias panorâmicas, telerradiografias em norma lateral e frontal e tomografias não computadorizadas (politomografias), podendo também ser utilizada a tomografia computadorizada.

\section{Radiografias Periapicais}

As radiografias periapicais proporcionam imagens de precisão e qualidade de resolução fornecendo informações iniciais em casos de suspeita de impactações. Também possibilitam a avaliação da presença e tamanho do folículo, assim como a integridade da coroa e raiz do dente.

Permitem uma avaliação bidimensional podendo relacionar o canino com os dentes vizinhos, localizando-os no sentido mésio-distal ou verticalmente. Para a avaliação vestíbulo-lingual do canino, uma segunda tomada radiográfica deve ser realizada utilizando-se a técnica de Clark, que consiste, basicamente, na angulação horizontal do cone da primeira para a segunda tomada.

Segundo Ericson e Kurol ${ }^{6}$, as radiografias periapicais associadas à análise clínica são suficientes para determinar com precisão a posição do canino em $92 \%$ dos casos.

\section{Radiografias Oclusais}

As radiografias oclusais ajudam na determinação da posição no sentido vestíbulo-lingual do canino impactado e junto com as radiografias periapicais, proporcionam a visualização da sua relação com outros dentes.

Segundo Bishara et al. (1976), Jacobs (1986) e Shroff (1997 apud ALMEIDA et al., 2001) ${ }^{1}$, demonstram bem a orientação horizontal do canino e a posição da coroa e ápice em relação aos outros dentes. Porém, nos casos de sobreposição dos caninos com os dentes adjacentes, há limitações na utilização desta técnica radiográfica. 


\section{Radiografias Panorâmicas}

A radiografia panorâmica é extremamente útil para determinar a posição de caninos não irrompidos em dois planos do espaço, além de fornecer uma satisfatória indicação da altura do canino e sua relação com o plano sagital mediano, fornecem ainda, informações sobre a sua inclinação.

As radiografias panorâmicas proporcionam informações limitadas quanto ao posicionamento vestíbulo-lingual do dente impactado. Segundo Lindauer et al. (1992) e Shroff (1997 apud ALMEIDA et al. ${ }^{1}$ ), a relação da cúspide do canino com a metade distal da raiz do incisivo lateral, tem sido empregada como um bom método para a visualização da impactação por palatina.

\section{Telerradiografias em Norma Lateral e Frontal}

As telerradiografias em norma lateral e frontal podem, em alguns casos, auxiliar na determinação da posição do canino impactado e relacioná-lo com as estruturas faciais vizinhas, como o seio maxilar e o soalho da cavidade nasal ${ }^{1,3}$.

Segundo estes autores, a telerradiografia em norma frontal permite avaliar a posição vestíbulo-lingual do canino, assim como a sua inclinação axial neste sentido. Por outro lado, a telerradiografia em norma lateral possui utilidade na determinação da inclinação mésio-distal e na distância vertical que o canino deve percorrer, para ser alinhado no arco.

\section{Tomografias não computadorizadas (Politomografias)}

A politomografia é uma técnica radiográfica que permite a verificação com maior precisão da relação do canino impactado com o incisivo lateral permanente, bem como define a real extensão de uma possível reabsorção, ocorrência de anquilose e dilaceração. A avaliação da condição da raiz de incisivo lateral é de grande importância para o clínico em função da alta incidência de reabsorções destes dentes, pela irrupção ectópica dos caninos.

Ericson e $\mathrm{Kurol}^{6}$, verificaram que, em 40\% dos casos de reabsorções dos incisivos laterais pelos caninos impactados, a extensão destas reabsorções era adequadamente observada somente com o emprego das tomografias não computadorizadas.

\section{CONDUTAS DE TRATAMENTO}

Diagnosticada a impactação do canino, pode-se considerar várias possibilidades de tratamento:

1) Não tratar o caso se o paciente assim o desejar, no entanto, devemos fazer o acompanhamento para o controle de alguma condição patológica;

2) autotransplante do canino. Se um dente está severamente impactado, o autotransplante é uma possibilidade de tratamento. A reabsorção externa da raiz é a maior causa de fracasso. Aproximadamente 2/3 dos dentes transplantados são funcionais por 5 anos, mas apenas cerca de $1 / 3$ fica retido por 10 anos $^{18}$;

3) extração do canino impactado e movimentação do premolar para o seu espaço;

4) extração do canino e osteotomia para movimentar todo o segmento posterior;

5) restabelecimento da oclusão por meio de prótese; a extração dificilmente é considerada, exceto em raros casos, tais como canino anquilosado, com reabsorção externa ou interna, severa impactação ou dilaceração e

6) exposição cirúrgica e tracionamento ortodôntico.

Antes da exposição cirúrgica, o tratamento ortodôntico deve ser iniciado com os seguintes objetivos:

1) Conseguir espaço suficiente no arco dentário para acomodar o canino permanente.

2) Nivelar e alinhar os dentes até que um fio rígido possa ser colocado para evitar efeitos adversos produzidos pela força de tração como 
a intrusão de dentes adjacentes, constricção do arco ou alteração do plano oclusal, que comprometerão o controle dos movimentos.

Exposição cirúrgica permitindo a erupção espontânea: incisão cirúrgica dos tecidos que recobrem a coroa do dente impactado que é mantido exposto por meio de cimento cirúrgico. Observa-se que o dente exposto erupciona espontaneamente, mas de modo incontrolável onde quer que haja espaço disponível. Este fenômeno foi atribuído a uma força dos tecidos periodontais que direciona a coroa exposta para a área onde os tecidos foram cortados ${ }^{20}$. Quando a impactação está localizada perto do rebordo alveolar, a erupção espontânea pode ocorrer e nestes casos, o tratamento ortodôntico é exigido apenas para finalizar o alinhamento dos dentes ${ }^{12}$. Ocasionalmente algum dente poderá irromper para a posição correta após a exposição cirúrgica e remoção dos obstáculos para a erupção, mas isso é raro após a formação completa da raiz. Mesmo um dente bem direcionado requer força ortodôntica para trazê-lo à posição ${ }^{18}$.

Exposição cirúrgica e colocação de um acessório para posterior tracionamento: existem diversos dispositivos descritos na literatura que podem ser empregados para este fim.

A técnica do laço foi muito utilizada antes do advento da colagem de braquetes. Consiste em laçar o dente empregando fio ortodôntico que é torcido para que se adapte à região cervical da coroa possibilitando a tração. A transfixação, sugerida por Fournier et al. (apud RODRIGUES; TAVANO, 1991) $)^{21}$, consiste em fazer uma pequena perfuração atravessando o ângulo incisal do dente, permitindo que um fio ortodôntico fosse amarrado ao mesmo e fixado com resina acrílica ou composta. Há a desvantagem de, posteriormente, o dente necessitar tratamento restaurador, além do risco de exposições pulpares acidentais.

Antes da colagem direta, um pino ou parafuso podia ser posicionado na coroa do dente não irrompido e, em circunstâncias especiais, isso permanece como alternativa ${ }^{18}$. Devido à dificuldade de acesso ideal, este procedimento apresenta risco de se causar dano pulpar e destruição dentária.

Com a introdução da técnica do ataque ácido, a exposição cirúrgica da coroa pode ser limitada a uma área suficiente para acomodar a base do acessório e em combinação com cuidadoso procedimento ortodôntico de extrusão, não trarão efeitos nocivos nem para o dente impactado nem para os dentes adjacentes. Os principais problemas associados com este método são a dificuldade de higienização e o desconforto da ferida ${ }^{20}$.

Um fio de ligadura ou ligadura elastomérica pode então ser laçado ao redor do acessório antes do retalho ser posicionado e suturado. A tração ortodôntica para trazer o dente impactado para o arco deve começar o mais cedo possível após a cirurgia ou, não sendo possível, não demorar mais que 2 ou 3 semanas $^{18}$.

A "Mola Ballista" proposta por Jacoby ${ }^{10}$, consiste num sistema em que o dente é tracionado pela ação de uma mola que libera uma força contínua, pela ativação por meio de seu longo eixo. O canino, após a exposição cirúrgica, recebe um acessório do tipo lingual clets que será o dispositivo de ligação para a complementação do sistema de tracionamento.

Os aparelhos removíveis também podem ser utilizados para tracionamento de caninos impactados no palato. Após a etapa cirúrgica de exposição do canino impactado, obtém-se o modelo de trabalho, no qual será construído o aparelho removível. As desvantagens serão o emprego de uma força intermitente e a dependência na cooperação do paciente quanto ao uso do aparelho e troca dos elásticos para a manutenção da força de tracionamento ${ }^{1}$.

Apicectomia associada à exposição da coroa com fixação de dispositivos para o tracionamento: a técnica proposta por Puricelli (1987 apud RODRIGUES; TAVANO, 1991)21 tem in- 
dicação quando temos dilacerações na região do terço apical que impossibilita a movimentação do dente frente aos mecanismos convencionais de tração. Consiste no deslocamento de um retalho muco periostal com incisão na região do ápice do canino, já avaliada radiograficamente. A loja cirúrgica é então fechada e o dente começa a ser tracionado lentamente ( 2 a $3 \mathrm{~mm}$ em quatro a oito meses) e com forças leves (60 a 150 gramas) $)^{19}$.

Vardimon et al..$^{27}$, em 1991, apresentaram um método de atração magnética do dente impactado através de um braquete magnético colado neste dente e um imã intra-oral ligado a uma contenção do tipo Hawley. Esse método faz uma simulação do processo de erupção normal, expondo o dente em um tempo certo, mantendo um equilíbrio da junção esmaltecemento à crista alveolar, a gengiva inserida, fibras gengivais livres e o epitélio inserido. Outras vantagens desta técnica são: força leve de tração (reduz o rico de perda óssea); e orientação espacial (o magneto intra-oral direciona o dente impactado ectopicamente para erupcionar em um curso curvo, simulando o caminho de erupção normal, o que minimiza o risco de reabsorção radicular do dente vizinho).

\section{MÉTODO PROPOSTO DE TRAÇÃO DE CANINOS IMPACTADOS POR PALATINO}

Após a localização do canino retido por palatino utilizando os métodos vigentes (exame físico e de diagnóstico por imagem), passamos a preparar o paciente para receber a tração do elemento dentário impactado.

O método preconizado envolve o tratamento combinado cirúrgico-ortodôntico, e a manobra cirúrgica permitirá a colagem de um acessório para a tração do canino retido. A fase ortodôntica de tração será de três tempos, ou seja: Verticalização, Posicionamento e Extrusão.

Durante os anos em que atendemos inúmeros pacientes portadores de retenção do ca- nino superior, já empregamos o laçamento no colo do dente, perfuração no ápice da cúspide, rosqueamento de acessório na coroa do dente e finalmente com os métodos de colagem de acessórios, nosso trabalho foi bastante facilitado, principalmente, após o desenvolvimento de materiais que permitem a colagem em meio úmido.

$\mathrm{Na}$ preparação do paciente, instalamos o aparelho fixo com multicolagem dos braquetes e bandas nos molares. A ancoragem, porém, será pela lingual e para isto usamos os primeiro e segundo premolares e primeiro molar que receberão braquetes e acessório também por lingual. Após a colagem lingual, o fio 0,016" ou 0,018 " será passivo e receberá dobras em helicóide para facilitar a tração.

Depois de localizado o dente retido, através do exame físico e de diagnóstico por imagem, será realizado a exposição cirúrgica de uma área da coroa do canino, que será apenas o suficiente para acomodar a base do acessório que está conectado a um fio de amarrilho. O acessório deve ser colado de modo direto na coroa do canino. Antes da sutura, uma força deve ser empregada para testar a colagem. O retalho pode ser suturado em cima do acessório permitindo que o fio de tracionamento corra fora do retalho. Desta maneira, ocorre maior preservação dos tecidos periodontais. Recomenda-se que quando for necessária a remoção de tecido ósseo, esta seja realizada de forma conservadora, evitando a remoção em excesso.

Depois da cirurgia de exposição do canino e colagem do acessório, a fase de tração é iniciada com ancoragem por lingual. Liga-se o fio de amarrilho conectado ao acessório até a dobra em helicóide do fio que passa por lingual dos primeiro premolar, segundo premolar e primeiro molar permitindo verticalizar o dente impactado distribuindo a força por três dentes pela lingual, o que previne reabsorção de raízes de dentes adjacentes. Durante esta fase, radiogra- 
fias devem ser tomadas para o controle e avaliação da posição do dente.

Com o dente impactado já presente na cavidade oral após a Verticalização, o segundo movimento será o de Posicionamento. Quando o dente estiver próximo da linha de oclusão e permitir a colagem de braquete na posição correta, o fio de nivelamento poderá incorporar alças em "L" na mesial e distal do canino ou alça em "box" que serão utilizadas para completar o movimento.

Um terceiro movimento ainda será feito para a Extrusão do dente com a finalidade de alinhar e nivelar o canino restabelecendo sua função e estética na oclusão. Para esse movimento, recomenda-se aguardar um período de 1 a 2 meses para que ocorra o rearranjo tecidual e melhor acomodação do canino no arco dentário sem

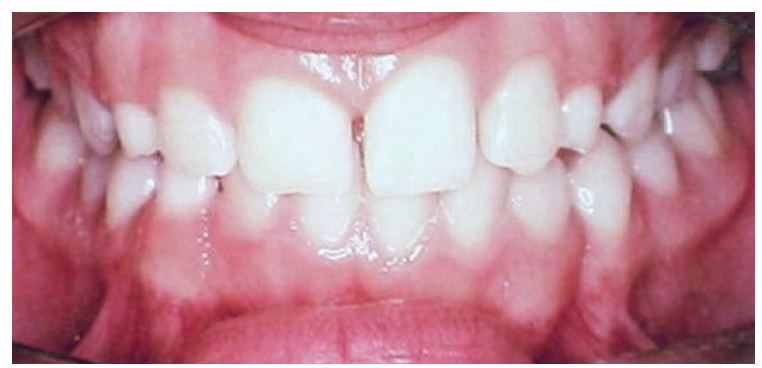

FIGURA 1 - Fotol frontal intrabucal inicial do paciente, mostrando caninos decíduos superiores no arco dentário.
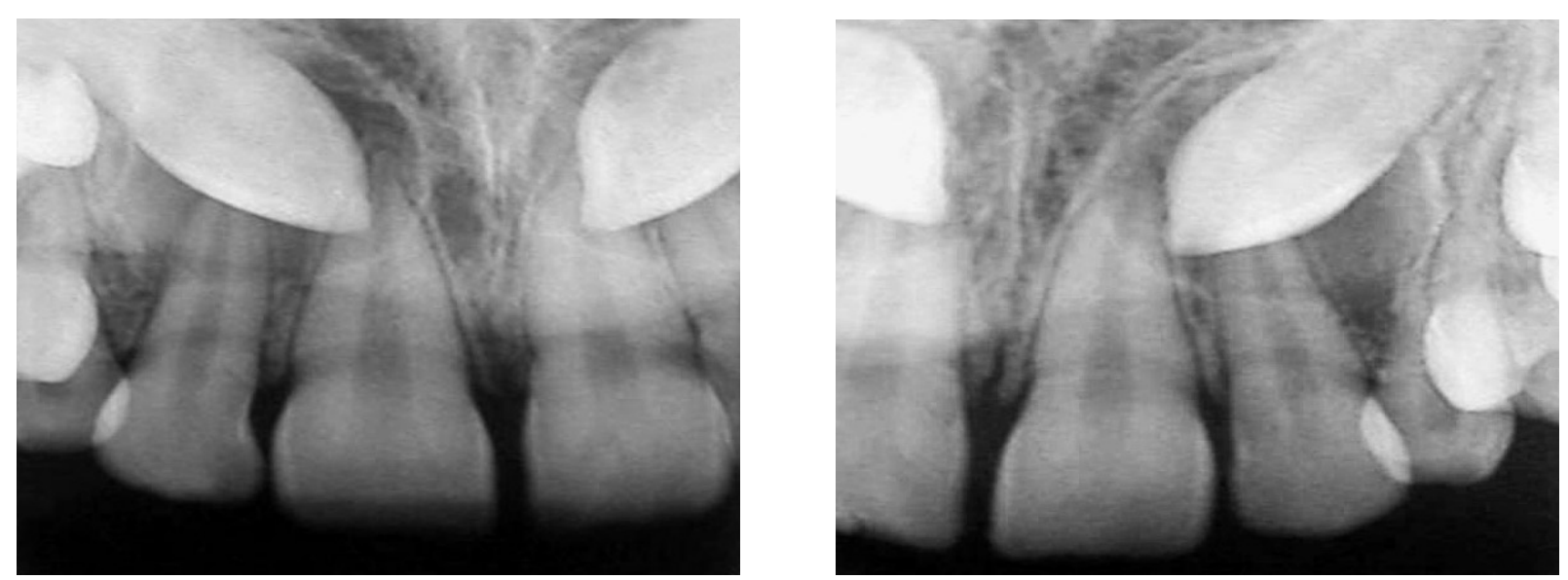

FIGURA 3, 4 - Radiografia periapical inicial mostrando os caninos permanentes impactados, com imagem radiolúcida ao redor das coroas sugerindo a presença de cisto. os prejuízos periodontais. A extrusão pode ser realizada com alças em "L" na mesial e na distal do canino para que fique com correta posição, angulação e inclinação.

Portanto, serão três os movimentos inseridos ao dente impactado. O primeiro tem como objetivo a verticalização do canino e será totalmente ancorado por lingual; o segundo movimento será de lingual para vestibular visando o seu posicionamento e o terceiro movimento será o da extrusão do dente até atingir o posicionamento mais favorável para a oclusão.

Nos pacientes em que empregamos este método de tração, não detectamos reabsorções nos dentes vizinhos e após o posicionamento do canino suas inserções estavam hígidas e dentro dos padrões periodontais.

Os movimentos devem ser feitos com for-

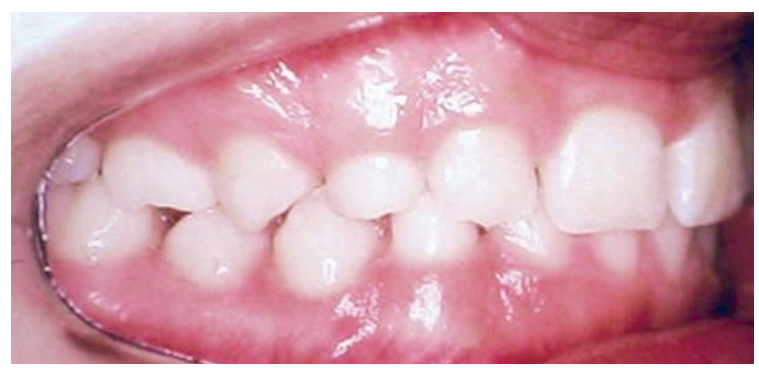

FIGURA 2 - Intrabucal lateral direita inicial mostra má-oclusão de Classe I de Angle, caninos e segundos molares decíduos no arco dentário. 
ças leves considerando o movimento de $1 \mathrm{~mm}$ por mês bastante próximo de uma força ótima. Considerando que o canino superior tem uma coroa alongada todos os movimentos serão demorados.

\section{CASO CLÍNICO}

Paciente D.T.R., sexo feminino, leucoderma, braquifacial, com idade cronológica de 13 anos, apresentou ao exame clínico retenção prolongada de caninos decíduos superiores (Fig. 1), dentadura mista, má-oclusão de Classe I (Fig. 2). Os exames complementares mostraram a impactação dos caninos superior direito e esquerdo por palatino com as cúspides próximas às raízes dos incisivos centrais e presença de

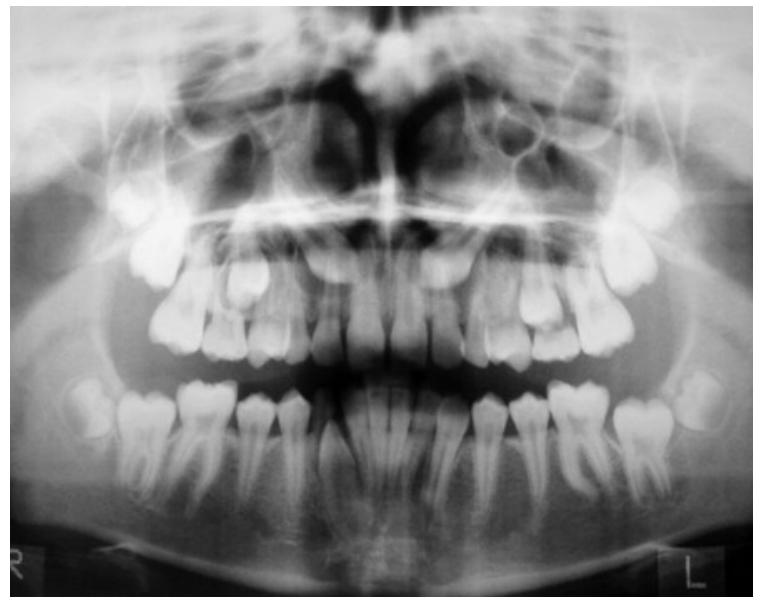

Figura 5 - Radiografia panorâmica mostrando a presença de todos os dentes permanentes e caracterizando a retenção prolongada dos caninos superiores decíduos e segundos molares superiores decíduos. imagem radiolúcida sugerindo formação de cisto (Fig. 3, 4).

Para o tratamento do caso foram indicadas as extrações dos segundos molares decíduos superiores após a confirmação radiográfica da presença dos dentes permanentes correspondentes (Fig. 5) e avaliação em norma lateral da posição dos caninos superiores permanentes (Fig. 6). Os caninos decíduos superiores foram mantidos no arco até a exposição cirúrgica dos caninos permanentes para colagem de acessório.

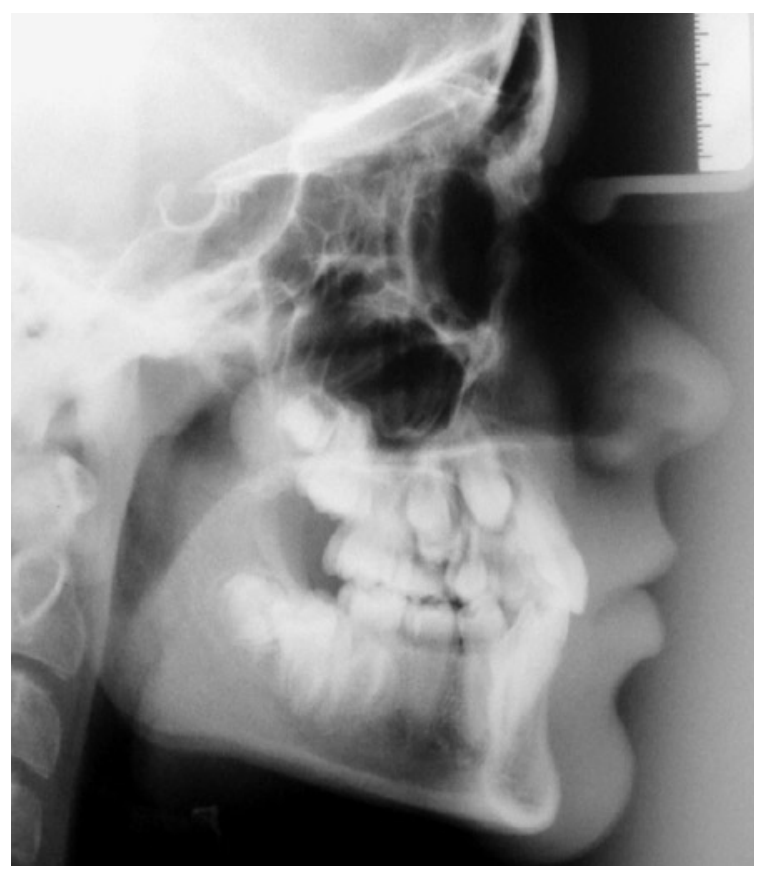

FIGURA 6 - Telerradiografia em norma lateral, servindo não somente para confecção do traçado cefalométrico como também no auxilio da visualização dos caninos superiores permanentes.
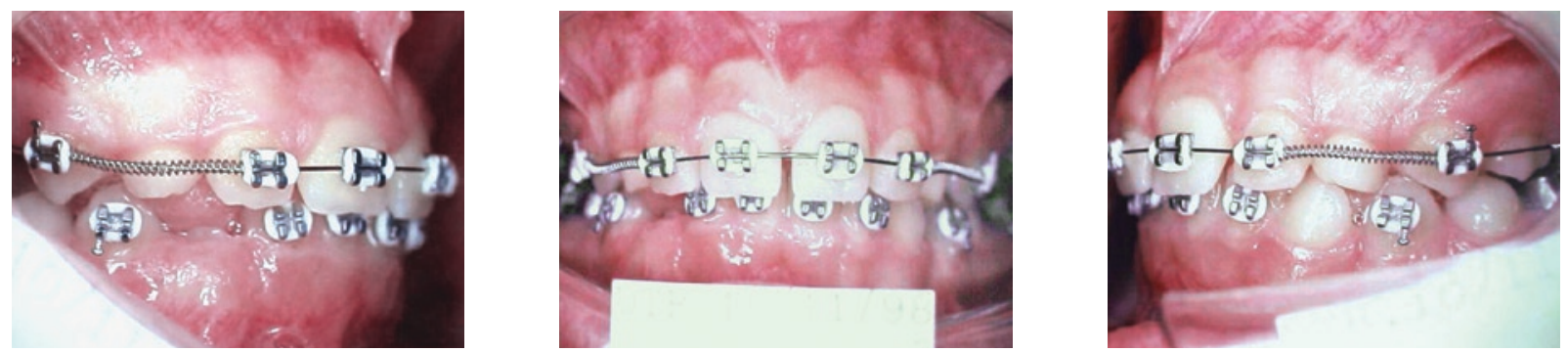

FIGURA 7 - 9 - Fase de nivelamento inicial, preparando 0 arco dentário para posterior fase cirúrgica. Nesta fase ainda podemos manter os caninos superiores decíduos no arco dentário. 
A fase seguinte do tratamento consistiu na montagem de aparelho fixo superior e inferior, com bandagem dos primeiros molares superiores e inferiores e colagem de braquetes nos demais dentes.

O nivelamento foi realizado com fios de $\mathrm{NiTi}$ e aço de secção redonda com mola aberta para recuperação de espaço dos caninos superiores impactados. Nesta fase, preparamos o arco superior para o tracionamento dos caninos impactados (Fig. 7-9).

Procedeu-se, então, a segunda fase do tratamento com a exposição cirúrgica das coroas dos caninos de forma conservadora e suficiente para permitir a colagem dos acessórios auxiliares conectados a um segmento de fio de amarrilho 0,20 mm. Os acessórios foram colados de modo direto nas coroas dos caninos e uma força foi empregada para testar a colagem antes do repo- sicionamento e sutura do retalho (Fig. 10-12).

Depois da cirurgia, a fase de tracionamento foi iniciada ligando o fio de amarrilho conectado ao fio de nivelamento permitindo o movimento inicial de verticalização dos caninos.

Após a verticalização, mudamos a direção de tração, orientando a mesma no sentido oclusal, ou seja, agora o movimento é visando o posicionamento dos caninos (Fig. 13-15).

Somente após a verticalização, os caninos foram movimentados em direção vestibular objetivando o correto posicionamento e alinhamento final. Os braquetes dos caninos foram recolados na posição correta para que o alinhamento e nivelamento fossem adequados na fase final do tratamento (Fig. 16-18).

Um período de 1 mês foi aguardado antes de se completar o alinhamento e nivelamento dos caninos, para permitir o rearranjo tecidual,

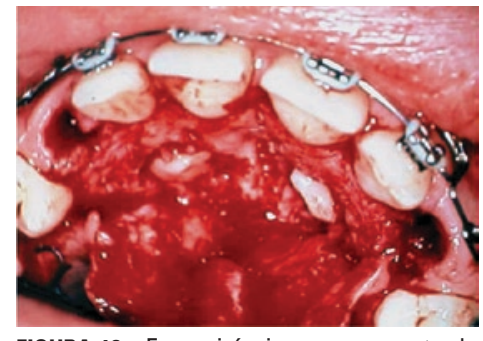

FIGURA 10 - Fase cirúrgica, no momento de exposição das coroas do caninos permanentes e remoção dos caninos decíduos.

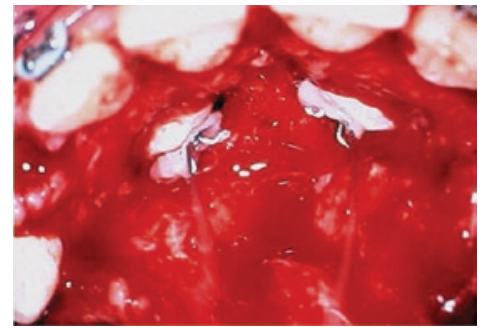

FIGURA 11 - Fase cirúrgica, no momento da colagem dos acessórios nos caninos permanentes.

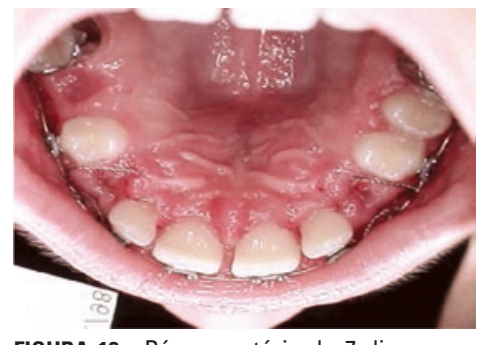

FIGURA 12 - Pós operatório de 7 dias, mostrando os fios de amarrilho que foram fixados nos acessórios na fase cirúrgica.
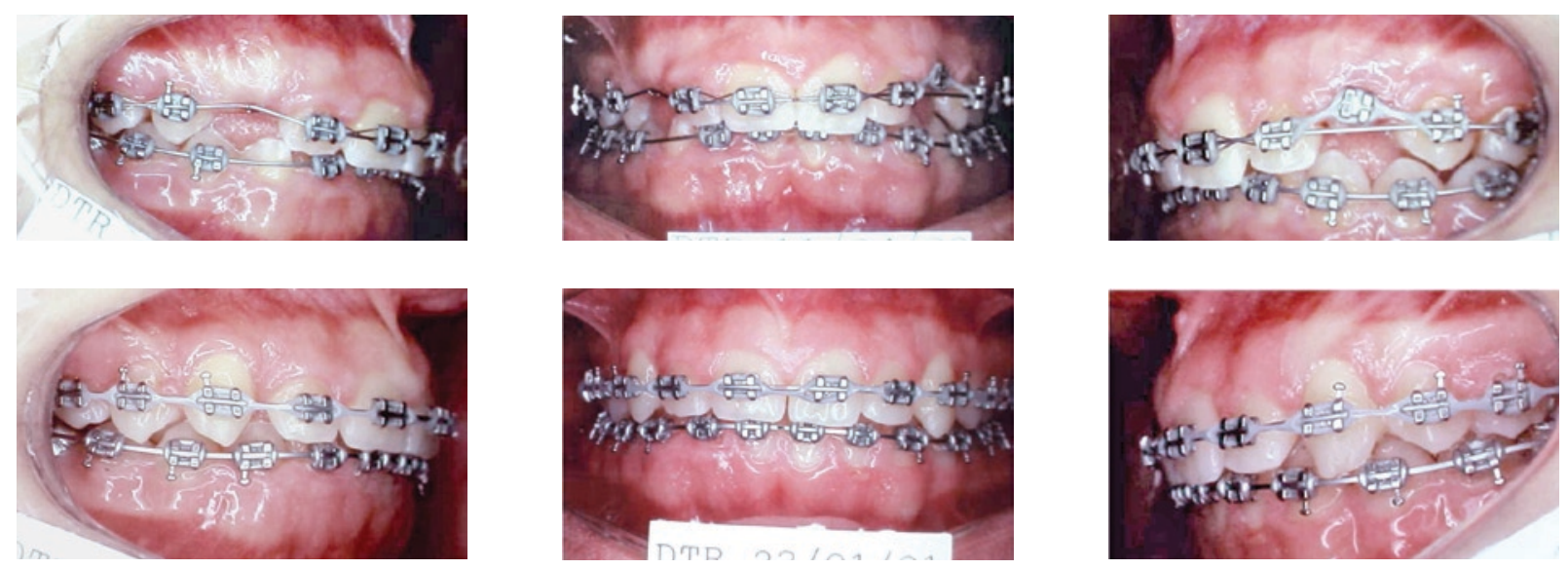

FIGURA 13 - 18 - Fase do nivelamento que consiste em verticalização, posicionamento e extrusão dos caninos superiores permanentes. 


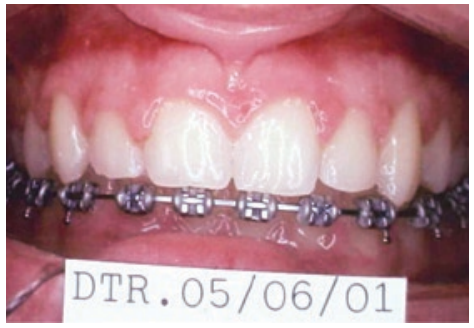

FIGURA 19 - Caninos tracionados e remoção da aparotologia fixa superior.

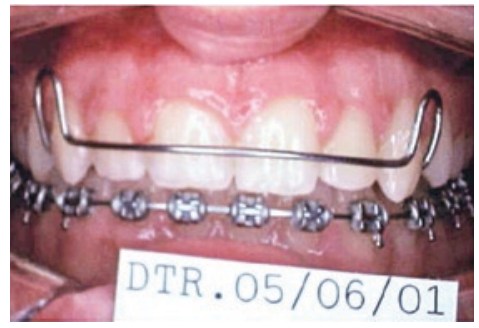

FIGURA 20 - Utilização de aparelho de contenção removível.

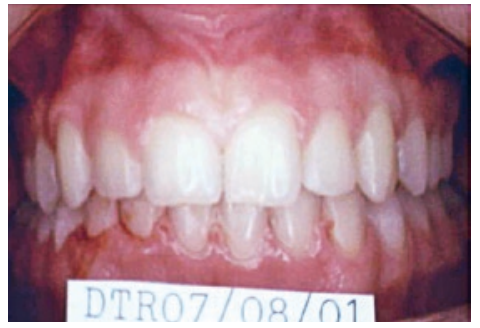

FIGURA 21 - Remoção da aparotologia fixa inferior.

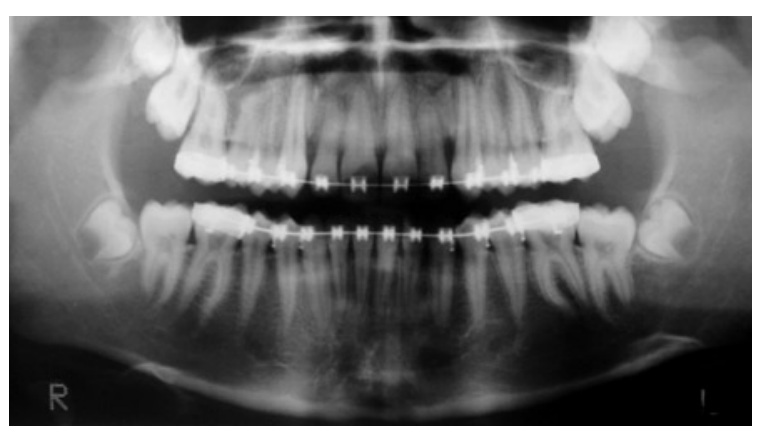

FIGURA 22 - Radiografia panorâmica final.

evitando-se os problemas periodontais. $\mathrm{O}$ movimento de extrusão foi realizado com fios de NiTi e aço de calibre $0,016 "$.

O período do procedimento cirúrgico até a finalização do alinhamento e nivelamento dos caninos foi de 24 meses e todo o tratamento teve acompanhamento radiográfico para o controle e avaliação dos caninos impactados.

Os movimentos foram feitos com forças leves e julgamos que um movimento de $1 \mathrm{~mm}$ por mês esteja bastante próximo de uma força ótima. Considerando que o canino superior tem uma coroa alongada, todos os movimentos serão demorados.

O tratamento para o reposicionamento dos caninos permanentes impactados foi realizado com êxito e após a finalização do caso, os caninos mostraram um bom posicionamento e prognóstico favorável quanto à estabilidade (Fig. 19-21).
Radiograficamente, não foram observados sinais de arredondamento dos ápices radiculares dos dentes adjacentes utilizados como ancoragem, nem alterações nas inserções periodontais (Fig. 22).

Nos casos de caninos impactados no palato, nossa proposta é fazer a tração em 3 tempos, ou seja, verticalização, posicionamento e extrusão, evitando que força de ancoragem seja exercida sobre os incisivos na primeira fase, utilizando-se a ancoragem lingual. $O$ uso de fios leves proporciona uma movimentação mais segura. U1timamente temos utilizado os fios TMA que aceitam a construção de alças e apresentam memória prolongada.

Durante os anos em que atendemos pacientes portadores de impactação do canino superior, podemos notar a grande variação de métodos como o laçamento no colo de dente, perfuração da ponta da cúspide, rosqueamento de acessório na coroa do dente e, finalmente, com os métodos de colagem, nosso trabalho foi bastante facilitado, principalmente, após o desenvolvimento de materiais que permitem a colagem em meio úmido.

Nos inúmeros pacientes em que empregamos o método de tração, não detectamos reabsorções nos dentes vizinhos e após o posicionamento do canino, as inserções periodontais estavam hígidas e dentro dos padrões tido como normais. Os resultados mostraram-se estáveis e com os caninos bem posicionados durante os retornos pós-tratamento dos pacientes. 


\section{DISCUSSÃO}

O paciente e/ou responsáveis devem estar cientes das vantagens e riscos do tratamento, como, por exemplo, a anquilose, a perda de vitalidade do dente, as reabsorções do canino e dentes adjacentes, perda do tecido de sustentação e o tempo de tratamento. Um canino num paciente entre 13 e 19 anos pode ser freqüentemente trazido para o arco por tração ortodôntica após a exposição cirúrgica. Em pacientes mais velhos, há um risco aumentado de que o dente impactado tenha tornado-se anquilosado, mesmo adolescentes correm o risco de que a exposição possa levar o dente a anquilose ${ }^{18}$.

As impactações dentárias ocorrem como resultado dos desvios na seqüência normal do desenvolvimento da oclusão. Além disso, dentes impactados podem causar vários problemas como reabsorção das raízes dos dentes vizinhos, perda do comprimento do arco, formação de cisto dentígeno, infecções locais, dor reflexa etc $^{20}$. Depois dos terceiros molares, os caninos superiores permanentes têm a maior incidência de impactação $0^{5,7,12,14,20,26}$, manifestando-se estatisticamente em $2 \%$ da população. Sua incidência é aproximadamente duas vezes maior no sexo feminino podendo ocorrer de forma uni ou bilateral. Aproximadamente, $80 \%$ a $90 \%$ dos caninos impactados estão por palatino e 10\% a $20 \%$ por vestibular ${ }^{5,23}$. Entretanto, Jacoby ${ }^{11}$ argumenta que os caninos impactados por palatino raramente erupcionam espontâneamente, enquanto que os impactados por vestibular podem erupcionar espontaneamente em uma posição ectópica, assim, o limite entre a impactação e erupção ectópica por vestibular não está absolutamente determinado, dificultando o estabelecimento de uma relação entre caninos impactados por palatino e por vestibular. Jarjoura, Crespo e Fine ${ }^{12}$, relataram ainda que essa relação está apropriada para os europeus e americanos e parece ser invertida entre os asiáticos.

Quanto a impactação do canino no palato, parece haver duas correntes ideológicas em relação aos fatores etiológicos. Uma que, além de causas locais como deficiência de tamanho do arco, retenção prolongada ou perda precoce, anquilose, trauma e etc., estabelece ainda a ausência de guia de erupção para o canino por parte de um incisivo lateral superior de tamanho diminuído ou ausente $e^{2,3,12,19,23}$. A outra defendida por Peck et al. ${ }^{16,17}$, que afirma estar fortemente ligada a fatores genéticos, já que as impactações do canino no palato costumam acontecer associadas a outras anomalias controladas geneticamente.

A literatura não é unânime no que diz respeito à quantidade de força utilizada para o tracionamento, entretanto, os movimentos devem ser feitos com forças leves e consideramos o movimento de $1 \mathrm{~mm} / \mathrm{mês}$ bastante próximo da força ótima.

É imperiosa a movimentação controlada e cuidadosa do canino impactado pelo lado palatino, sendo necessário que a componente inicial de força seja vertical e posterior para se evitar danos às raízes dos dentes adjacentes. Somente após a verticalização, o canino deve ser movimentado em direção vestibular aproximando o dente da linha de oclusão e, finalmente, o terceiro movimento de extrusão visa o correto posicionamento e alinhamento do dente na arcada dentária. É importante, ainda, aguardar um período de 1 a 2 meses, para o rearranjo tecidual, antes do movimento de extrusão para se evitar problemas periodontais.

Quando existir a indicação da exodontia do primeiro premolar, a fim de obter espaço para o canino impactado, recomenda-se que a mesma não seja realizada antes de descartar a possibilidade de anquilose ou outros problemas como dilaceração ou reabsorção.

\section{CONCLUSÕES}

Podemos concluir que o tratamento de caninos impactados no palato é extremamente 
complexo e deve-se tentar de todas as formas reposicionar estes dentes no arco dentário do paciente, devido a sua importância funcional e estética no desenvolvimento da oclusão normal de um indivíduo.

O diagnóstico precoce torna o prognóstico mais favorável, evitando possíveis complicações como reaborções radiculares dos dentes adjacentes, anquilose do canino impactado ou processos infecciosos e degenerativos decorrentes da impactação dentária.

O prognóstico do tratamento irá depender dos exames complementares para determinar a posição correta do canino impactado, e possíveis complicações que inviabilizariam seu tracionamento como anquilose, dilaceração ou posicionamento muito profundo.

Com o desenvolvimento das técnicas de colagem de braquetes, foi possível um tratamento cirúrgico conservador para expor a coroa do canino impactado e colagem de um acessório ortodôntico, através do qual se faz o tracionamento do dente.

Em nossa proposta de método para tração de caninos no palato, a mecânica de tração se faz em três tempos: Verticalização, Posicionamento de lingual para vestibular e Extrusão. A ancoragem para tração será por lingual distribuída entre os primeiros e segundos premolares e primeiro molar, enquanto o nivelamento dentário superior e a recuperação de espaço para o canino se faz por meio de aparelho ortodôntico fixo convencional. Isto permite uma tração controlada, sem riscos de reabsorções radiculares nos dentes adjacentes ou perda de higidez nos tecidos de sustentação.

No caso clínico apresentado, as ativações foram realizadas procurando tracionar canino não mais que 1 milímetro ao mês. Isto proporcionou um tratamento eficiente com força e direcionamento do canino impactado bem controlados ortodonticamente e sem injúrias ou desconforto para o paciente.

Todos os demais casos tratados não mostraram reabsorções radiculares e os caninos tracionados apresentaram-se com boas inserções, constatado por meio de sondas periodontais ao final do tratamento.

\title{
Palatine impacted permanent maxillary canines: diagnose and therapeutics
}

\begin{abstract}
The teeth follow a favorable sequence of eruption on the development of a normal occlusion, but some disturbance of that mechanism at the period of transition of the mixed denture for the permanent one, may provoke alterations in the sequence or even in the eruption path, resulting in impactation of teeth. The permanent maxillary canine, after the third molars, is the most commonly impacted tooth, especially at the palatine area, even though enough space be present for its alignment in the dental arcade. If a precocious diagnosis is not possible, efforts should be used for replace the tooth in the dental arch avoiding its extraction, because its importance for the aesthetic balance and the functional occlusion. The not diagnosed or inadequately negotiated cases may incur mechanical, infectious or neoplasics disturbances. The prognostic depends on the position of the maxillary canine with relation to the adjacent structures and to the possibility of orthodontic movement. The present work approaches the main factors to be considered in the cases of impacted permanent maxillary canine, such as eruption process, etiology, diagnosis and a proper way of palatal impacted canines traction used by ower orthodontic team. A clinical case will also be presented which opted for a surgical-orthodontic treatment, showing a traction technique which have been demonstrated quite efficient in palatal impacted canines cases.
\end{abstract}

Key words: Maxillary canine impactation. Etiology. Impactation of teeth. 


\section{REFERÊNCIAS}

1. ALMEIDA, R. R.; FUZIY, A.; ALMEIDA, M. R.; ALMEIDA PEDRIN, R. R.; HENRIQUES, J. F. C.; INSABRALDE, C. M. B. Abordagem da impactação e/ou irrupção ectópica dos caninos permanentes: considerações gerais, diagnóstico e terapêutica. Rev. Dental Press Ortodon. Ortop. Facial, Maringá, v. 6, n. 1, p. 93-116, jan./fev. 2001.

2. BECKER, A.; SMITH, P.; BEHAR, R. The incidence of anomalous maxillary lateral incisors in relation to palatally-displaced cuspids. Angle Orthod., Appleton, v. 51, no. 1, p. 24-29, Jan. 1981.

3. BISHARA, S. E. Impacted maxillary canines: a review. Am. J. Orthod. Dentofacial Orthop., St. Louis, v. 101, no. 2, p. 159-170, Feb. 1992.

4. BRIN, I.; SOLOMON, Y.; ZILBERMAN, Y. Trauma as a possible etiologic factor in maxillary canine impaction. Am. J. Orthod. Dentofacial Orthop., St. Louis, v. 104, no. 2, p. 132-137, Aug 1993.

5. BROWN, N. L.; SANDY, J. R. Spontaneous improvement in position of canines from apparently hopeless positions. Int. J. Paediatr. Dent., Oxford, v. 11, no. 1, p. 64-68, Jan. 2001.

6. ERICSON, S.; KUROL, J. Radiographic examination of ectopically erupting maxillary canines. Am. J. Orthod. Dentofacial Orthop., St. Louis, v. 91, no. 6, p. 483-492, June 1987.

7. IRAMANEERAT, S.; CUNNINGHAM, S. J.; HORROCKS, E. N. The effect of two alternative methods of canine exposure upon subsequent duration of orthodontic treatment. Int. J. Paediatr. Dent., Oxford, v. 8, no. 2, p. 123-129, June 1998.

8. JACOBS, S. G. The impacted maxillary canine: further observations on aetiology, radiographic localization, prevention/interception of impaction, and when to suspect impaction. Aust. Dent. J., Sydney, v. 41, no. 5, p. 310-316, Oct. 1996.

9. JACOBS, S. G. Reducing the incidence of unerupted palatally displaced canines by extraction of deciduous canines: the history and application of this procedure with some case reports. Aust. Dent. J., Sydney, v. 43, no. 1, p. 20-27, 1998.

10. JACOBY, H. The "ballista spring" system for impacted teeth. Am. J. Orthod., St. Louis, v. 75, no. 2, p. 143-151, Feb. 1979.

11. JACOBY, H. The etiology of maxillary canine impactions. Am. J. Orthod., St. Louis, v. 84, no. 2, p. 125-132, Aug. 1983.

12. JARJOURA, K.; CRESPO, P.; FINE, J. B. Maxillary canine impactions: orthodontic and surgical management. Compend. Contin. Educ. Dent., Lawrenceville, v. 23, no. 1, p. 23-31, Jan. 2002.

13. LEWIS, P. D. Preorthodontic surgery in the treatment of impacted canines. Am. J. Orthod., St. Louis, v. 60, no. 4, p. 382-397, Oct. 1971.

14. MASON, C.; PAPADOKOU, P.; ROBERTS, G. J. The radiographic localization of impacted maxillary canines: a comparison of methods. Eur. J. Orthod., Oxford, v. 23, no. 1, p. 25-34, Feb. 2001.
15. MERMIGOS, J.; FULL, C. A. Surgical exposure and orthodontic positioning of an enerupted maxillary canine: case report. Pediatr. Dent., Chicago, v. 11, no. 1, p. 72-75, Mar. 1989

16. PECK, S.; PECK, L.; KATAJA, M. The palatally displacement as a dental anomaly of genetic origin. Angle Orthod., Appleton, v. 64, no. 4, p. 249-256, 1994.

17. PECK, S.; PECK, L.; KATAJA, M. Sense and nonsense regarding palatal canines. Angle Orthod., Appleton, v. 65, no. 2, p. 99-102, 1995.

18. PROFFIT, W. R. Ortodontia contemporânea. 2. ed. Rio de Janeiro: Guanabara Koogan, 1993

19. PURICELLI, E.; FRIEDRICH, C. C.; HORST, S. F. Canino retido por anquilose: tratamento cirúrgico ortodôntico. RGO, Rev. Gaucha Odontol., Porto Alegre, v. 41, n. 6, p. 360-362, nov./dez. 1993.

20. QUIRYNEN, M.; HEIJ, D. G. O.; ADRIANSENS, A.; OPDEBEECK, H. M.; STEENBERGHE, D. Periodontal health of orthodontically extruded impacted teeth: a split-mouth longterm clinical evaluation. J. Periodontol., Chicago, v. 71, no. 11, p. 1708-1714, Nov. 2000.

21. RODRIGUES, C. B. F.; TAVANO, O. Os caninos e seus envolvimentos no equilíbrio estético. Rev. Assoc. Paul. Cir. Dent., São Paulo, v. 45, n. 4, p. 529-534, jul./ago. 1991.

22. SANITÁ, S. F. Impactação dentária de caninos permanentes: conseqüências e relação com ortopedia funcional dos maxilares. Rev. Fac. Odontol. Porto Alegre, Porto Alegre, v. 36, n. 1, p. 8-11, ago. 1995.

23. SHELLHART, W. C.; JASPER, S.; ABRAMS, H.; WILSON, T. Case report: management of significant incisor root resorption associated with maxillary canine impaction. Angle Orthod., Appleton, v. 68, no. 2, p. 187-192, Apr. 1998.

24. SILVA FILHO, O. G.; FUGIO, N.; CAPELOZZA FILHO, L.; CAVASSAN, A. O. Irrupção ectópica dos caninos permanentes superiores: soluções terapêuticas. Ortodontia, São Paulo, v. 27, n. 3, p. 50-66, set./dez. 1994.

25. SILVA, H. A.; BORDON, A. K. C. B.; ABDO, R.; CHEDID, S. J.; NOUER, P. R. A. Surgical exposure for unerupted upper canine traction: clinical case. Ortodontia, São Paulo, v. 35, n. 1, p. 147-150, jan./mar. 2002.

26. STEWART, J. A.; HEO, G.; GLOVER, K. E.; WILLIAMSON, P. C.; LAM, E. W. N.; MAJOR, P. W. Factors that relate the treatment duration for patients with palatally impacted maxillary canines. Am. J. Orthod. Dentofacial Orthop., St. Louis, v. 119, no. 3, p. 216-225, Feb. 2001.

27. VARDIMON, A. D.; GRABER, T. M.; DRESCHER, D.; BOURAUEL, C. Rare earth magnets and impaction. Am. J. Orthod. Dentofacial Orthop., St. Louis, v. 100, no. 6, p. 494-511, Dec. 1991.
Endereço para correspondência
Mario Cappellette
Rua Salete n 200 - 10 andar
CEP: 02.016-001 - São Paulo / SP
E-mail: mjrcappellette@terra.com.br 